\title{
Synthesis of Alkoxylated Phenolic Resins Containing an Acetyl Group and Their Functionalization by Grignard Reaction
}

\author{
By Tadamasa NEMOTO, Isamu AMIR, and Gen-ichi KONISHI*
}

We successfully synthesized acetyl group-containing phenolic resins as novel reactive polymers. The addition-condensation of 2,4,6-trimethoxyacetophenone (1) with an equimolar amount of formaldehyde catalyzed by $12 \mathrm{~mol} / \mathrm{L} \mathrm{HCl}$ aq. proceeded homogeneously without side reactions to give polymer $3\left(M_{\mathrm{n}} 4800, M_{\mathrm{w}} / M_{\mathrm{n}} 1.3\right)$ in $32 \%$ yield. The FT-IR, ${ }^{1} \mathrm{H}$ NMR and ${ }^{13} \mathrm{C}$ NMR spectra of $\mathbf{3}$ revealed that it had arylene-methylene units on the polymer backbones. The terpolymerization from $\mathbf{1}$, 1,3,5-trimethoxybenzene (2) and formaldehyde was also carried out. When the feed ratio of $\mathbf{1}$ to $\mathbf{2}$ was $1: 1$, the content of $\mathbf{1}$ in the obtained polymer, $\mathbf{4}$, was found to be $25 \%$ by the ${ }^{1} \mathrm{H}$ NMR spectrum; hence, the reactivity of $\mathbf{1}$ was lower than that of $\mathbf{2}$. The reactions of 4 with Grignard reagents were carried out to evaluate the reactivity of acetyl groups in the obtained polymers. Their reactions proceeded at some parts of acetyl groups, so $\mathbf{4}$ can be applied as novel reactive phenolic resins. From thermogravimetric analyses, thermal stabilities of the functionalized polymers (6a-6d) are similar to that of $\mathbf{4}$, so it is expected that $\mathbf{4}$ have characters not only of the phenolic resins but also of the reactive polymers.

KEY WORDS: Novolac / Phenolic Resin / Reactive Polymer / Acetyl Group / Grignard Reaction / Addition-Condensation /

Phenolic resins (novolacs) $)^{1,2}$ were the first artificial plastics that were put to practical use in the last century. Furthermore, these resins are one of the most important thermosetting materials used in industries and have been frequently used as adhesives, curing agents, photoresists, polymer composites, etc. ${ }^{3}$ The significant characteristics of phenolic resins, such as heat stability and mechanical properties, are attributed to their rigid rod-like polymer backbone of "poly(phenylenemethylene)." Several studies have been conducted on oligomeric novolac-based resins $\left(M_{\mathrm{w}}<1000\right)$; however, the fabrication of such novolacs with high molecular weights has been difficult because of their poor solubility in organic solvents. ${ }^{1,2}$ Therefore, in order to realize phenolic resins that can be used as engineering plastics, novel phenolic resins with high molecular weights must be developed via the protection of phenolic hydroxyl groups by converting them to alkoxyl groups. ${ }^{5}$ Furthermore, the resins prepared in this manner exhibit better reactivities and solubilities and hence have a wide scope of applications.

Reactive polymers have attracted considerable interest of researchers, because their characteristics and functions can be enhanced to develop crosslinking agents, resist materials, expandable polymers, etc. ${ }^{6}$ We have already reported the synthesis of formyl group-containing novolacs in another paper. ${ }^{7}$ These novolacs have the potential to be used as reactive polymers in the condensation reaction with alkyl amine or diamine that results in imine conformation or gel formation; furthermore, the obtained gel demonstrated reversibility when treated with acids. By developing novel reactive novolacs that exhibit both thermal stability, which is comparable to that of conventional phenolic resins and high functionality, the applicability of novolacs can be enhanced significantly.

In this study, we carried out the addition-condensation of acetylated phenol derivatives with formaldehyde to yield novolacs containing suitable functional groups. In order to develop a novel phenolic novolac, we focused on carrying out the addition-condensation of an acetyl group-containing phenol derivative, 2,4,6-trimethoxyacetophenone (1). In organic chemistry, an acetyl group often undergoes reactions such as aldol condensation, oxidation, and hydrazone synthesis. Hence, by preparing a novolac containing an acetyl group, we can obtain a novel reactive novolac that can be used in the preparation of new thermally stable materials. Moreover, we demonstrate the use of phenol-based novolacs containing a protected hydroxyl group or alkoxylated group as a new class of high-performance phenolic resins. These novolacs exhibit higher solubility in organic solvents, better processability, and higher resistance to heat than the conventional phenolic resins. ${ }^{5}$ In our study, we used $\mathbf{1}$ as the acetylated phenol derivative for copolymerization with formaldehyde. We used 1,3,5-trimethoxybenzene (2) as a substrate in the preparation of a terpolymer of $\mathbf{1}, \mathbf{2}$ and formaldehyde; this terpolymer is expected to exhibit the characteristic properties of phenol derivative-based resins, such as good solubility in organic solvents, high thermal stability, and good processability. Furthermore, in order to investigate the reactivities of the polymers prepared in our study and to demonstrate their use as reactive polymers, we carried out the reactions of these polymers with organomagnesium bromides (Grignard reagents) derived from bromobenzene, 2-bromonaphthalene, 4-bromobiphenyl, and 
1-bromopyrene. We also investigated the thermal and the solution properties of the obtained polymers.

\section{EXPERIMENTAL}

\section{Materials}

Unless otherwise noted, all reagents and chemicals were purchased from TCI and utilized without further purification. 2,4,6-Trimethoxyacetophenone (1) and 1,3,5-trimethoxybenzene (2) were obtained from Lancaster and Wako Pure Chem., respectively. Magnesium turnings and paraformaldehyde were purchased from Nacalai Tesque. The dehydrated tetrahydrofuran without any stabilizers was obtained from Kanto Chem.

\section{Instruments}

All the ${ }^{1} \mathrm{H}$ NMR and ${ }^{13} \mathrm{C}$ NMR spectra were obtained in $\mathrm{CDCl}_{3}$ and recorded by a JEOL LNM-EX 400 instrument with tetramethylsilane (TMS) as the internal standard. The Fourier transfer infrared (FT-IR) spectra were recorded by using a JASCO FT-IR 460 plus spectrometer. Gel permeation chromatography (GPC) was carried out by a JASCO UV-2075 detector and a JASCO RI-2031 detector (TOSOH TSKgel $\mathrm{G} 3000 \mathrm{H}_{\mathrm{XL}}$ or $\mathrm{G} 4000 \mathrm{H}_{\mathrm{XL}}$ column) using tetrahydrofuran (THF) as an eluent after calibration with polystyrene standards. Thermogravimetric analysis (TGA) was performed using a SII TG/DTA 6200 (SEIKO Instrument Inc.) with a heating rate of $10{ }^{\circ} \mathrm{C} / \mathrm{min}$ in a nitrogen atmosphere. The solution properties of the polymers were estimated by a Viscotek Triple Detector TDA302 system and its analysis program (Omni Sec3.0) using THF as an eluent. High Pressure Liquid Chromatography (HPLC) was carried out by an LC-9204 system with a JAI UV3702 detector (Shodex HF-2002) using THF as an eluent.

Addition-Condensation of 2,4,6-Trimethoxyacetophenone (1) with Formaldehyde. Paraformaldehyde $(0.30 \mathrm{~g}, 10 \mathrm{mmol}$ as a formaldehyde unit) and THF $(10 \mathrm{~mL})$ were added to a $30 \mathrm{~mL}$ round bottom flask. After stirring for a few minutes, $12 \mathrm{~mol} / \mathrm{L}$ $\mathrm{HCl}$ aq. $(2.0 \mathrm{~mL})$ was added at $0{ }^{\circ} \mathrm{C}$, and then, 2,4,6-trimethoxyacetophenone $(2.1 \mathrm{~g}, 10 \mathrm{mmol})$ was continuously added. After the mixture was stirred with a reflux condenser at $50{ }^{\circ} \mathrm{C}$ for $15 \mathrm{~h}$, it was poured into methanol to give the objective product $(\mathbf{3})$ as a colorless precipitate in $32 \%$ yield. ${ }^{1} \mathrm{H} \mathrm{NMR}\left(\mathrm{CDCl}_{3}, 400 \mathrm{MHz}, \delta, \mathrm{ppm}\right): 2.36-2.50$ (Ar-CO$\left.\mathrm{CH}_{3}\right)$, 3.00-3.74 (Ar-OCH$), 3.74-4.10\left(\mathrm{Ar}-\mathrm{CH}_{2}-\mathrm{Ar}\right), 6.04-$ 6.24 (aromatic $H$ ).; ${ }^{13} \mathrm{C} \mathrm{NMR}\left(\mathrm{CDCl}_{3}, 100 \mathrm{MHz}, \delta, \mathrm{ppm}\right)$ : 17.5-21.0 (Ar- $\left.\mathrm{CH}_{2}-\mathrm{Ar}, \mathrm{Ar}-\mathrm{CO}-\mathrm{CH}_{3}\right)$, 55.0-63.0 (Ar-OCH$)$, 90.5-93.0 (aromatic $C-\mathrm{H}$ ), 115.0-117.5, 122.5-125.0 (aromatic $C-\mathrm{CH}_{2}-$ ), 153.5-160.5 (aromatic $C-\mathrm{OCH}_{3}$ ), 202.2$204.0\left(\mathrm{Ar}-\mathrm{CO}-\mathrm{CH}_{3}\right)$; FT-IR $\left(\mathrm{KBr}, \mathrm{cm}^{-1}\right)$ : 2941, $2832\left(-\mathrm{CH}_{2}-\right)$, $1700(\mathrm{C}=\mathrm{O}), 1597$ (aromatic $\mathrm{C}=\mathrm{C}), 1106\left(\mathrm{Ar}-\mathrm{O}-\mathrm{CH}_{3}\right)$.

Addition-Condensation of 2,4,6-Trimethoxyacetophenone (1) and 1,3,5-Trimethoxybenzene (2) with Formaldehyde. The typical polymerization is as follows. Paraformaldehyde $(0.30 \mathrm{~g}$, $10 \mathrm{mmol}$ as a formaldehyde unit) and THF $(20 \mathrm{~mL})$ were added to a $30 \mathrm{~mL}$ round bottom flask. After stirring for a few minutes, $12 \mathrm{~mol} / \mathrm{L} \mathrm{HCl}$ aq. $(5.0 \mathrm{~mL})$ was added at $0{ }^{\circ} \mathrm{C}$, and then, 2,4,6trimethoxyacetophenone (1) $(1.1 \mathrm{~g}, 5.0 \mathrm{mmol})$ and 1,3,5-tri- methoxybenzene (2) $(0.85 \mathrm{~g}, 5.0 \mathrm{mmol})$ were continuously added. After the mixture was stirred at $50{ }^{\circ} \mathrm{C}$ for $6 \mathrm{~h}$, it was poured into methanol to give the objective product (4) as a colorless precipitate in $22 \%$ yield. ${ }^{1} \mathrm{H} \mathrm{NMR}\left(\mathrm{CDCl}_{3}, 400 \mathrm{MHz}\right.$, $\delta, \mathrm{ppm}):$ 2.36-2.50 ( $\left.\mathrm{Ar}-\mathrm{CO}-\mathrm{CH}_{3}\right), 3.20-3.63\left(\mathrm{Ar}-\mathrm{OCH}_{3}\right)$, 3.67-4.00 (Ar- $\left.\mathrm{CH}_{2}-\mathrm{Ar}\right), 6.04-6.32$ (aromatic $H$ ).; FT-IR (KBr, $\mathrm{cm}^{-1}$ ): 2941, $2832\left(-\mathrm{CH}_{2}-\right), 1700(\mathrm{C}=\mathrm{O}), 1597$ (aromatic $\mathrm{C}=\mathrm{C}), 1105\left(\mathrm{Ar}-\mathrm{O}-\mathrm{CH}_{3}\right)$.

Typical Procedure for Grignard Reagents (5a-5d). Magnesium turnings $(0.74 \mathrm{~g}, 30 \mathrm{mmol})$ were taken in a $200 \mathrm{~mL}$ three necked flask and dried under reduced pressure. Dehydrated diethyl ether $\left(\mathrm{Et}_{2} \mathrm{O}\right)(50 \mathrm{~mL})$ and 1,2-dibromoethane $(2.0 \mathrm{~mL})$ were added to the flask in an argon atmosphere. After stirring the mixture at room temperature, the dehydrated $\mathrm{Et}_{2} \mathrm{O}(40 \mathrm{~mL})$ solution of aryl bromide $(10 \mathrm{mmol})$ was added to the reaction mixture at $0{ }^{\circ} \mathrm{C}$. After stirring the mixture for $1 \mathrm{~h}$ at room temperature, it was refluxed for $1 \mathrm{~h}$. Finally, the tannish $\mathrm{Et}_{2} \mathrm{O}$ solution was obtained and utilized in the Grignard reaction without any purification and titration; 5a: phenylmagnesium bromide; 5b: 2-naphthylmagnesium bromide; 5c: 4-biphenylmagnesium bromide; 5d: 1-pyrenylmagnesium bromide.

Reaction of Polymer 4 with Grignard Reagents (5a-5d). The typical Grignard reaction is as follows. Polymer 4 (the content of acetophenone unit is $25 \%$ estimated by the ${ }^{1} \mathrm{H}$ NMR spectrum) $(0.20 \mathrm{~g}, 0.26 \mathrm{mmol}$ of acetyl group) and THF $(20 \mathrm{~mL})$ were added to a $100 \mathrm{~mL}$ two necked flask in an argon atmosphere. After adding the $\mathrm{Et}_{2} \mathrm{O}$ solution of Grignard reagents $(6.0 \mathrm{mmol})$ to the reaction mixture, the solution was stirred continuously for $1 \mathrm{~h}$ at room temperature, and then, stirred for $1 \mathrm{~h}$ at $50{ }^{\circ} \mathrm{C}$. $5 \mathrm{~mol} / \mathrm{L} \mathrm{NH} \mathrm{NH}_{4} \mathrm{Cl}$ aq. $(100 \mathrm{~mL})$ and $1.2 \mathrm{~mol} / \mathrm{L} \mathrm{HCl}$ aq. $(100 \mathrm{~mL})$ were added to the reaction solution in order to quench the non-reacted organomagnesium reagent. The organic components were extracted by chloroform $(300 \mathrm{~mL})$, and the chloroform solution was washed several times with $0.5 \mathrm{~mol} / \mathrm{L} \mathrm{NaHCO}_{3}$ aq. $(100 \mathrm{~mL})$ and water. The solution was dried over $\mathrm{MgSO}_{4}$ and evaporated to $10 \mathrm{~mL}$. Finally, the resulting solution was poured into methanol $(100 \mathrm{~mL})$ to obtain the objective product $(\mathbf{6 a}-\mathbf{6 d})$.

6a: Yield: $40 \%$ (colorless powder): ${ }^{1} \mathrm{H} \mathrm{NMR}\left(\mathrm{CDCl}_{3}, 400\right.$ $\mathrm{MHz}, \delta, \mathrm{ppm}): 1.82-1.95\left(\mathrm{Ar}_{2}-\mathrm{C}(\mathrm{OH})-\mathrm{CH}_{3}\right), 2.34-2.51$ (Ar$\left.\mathrm{CO}-\mathrm{CH}_{3}\right), 2.91-3.72\left(\mathrm{Ar}-\mathrm{O}-\mathrm{CH}_{3}\right), 3.72-4.20\left(\mathrm{Ar}-\mathrm{CH}_{2}-\mathrm{Ar}\right)$, 5.78-6.32 (aromatic $H$ ), 7.06-7.25, 7.34-7.45 (phenyl $H$ ).; FT-IR $\left(\mathrm{KBr}, \mathrm{cm}^{-1}\right): 3464(-\mathrm{OH}), 2938,2831\left(-\mathrm{CH}_{3}\right), 1701$ $(\mathrm{C}=\mathrm{O}), 1598$ (aromatic $\mathrm{C}=\mathrm{C}), 1107\left(\mathrm{Ar}-\mathrm{O}-\mathrm{CH}_{3}\right)$.

6b: Yield: $37 \%$ (colorless powder): ${ }^{1} \mathrm{H} \mathrm{NMR}\left(\mathrm{CDCl}_{3}, 400\right.$ $\mathrm{MHz}, \delta, \mathrm{ppm}): 1.88-2.13\left(\mathrm{Ar}_{2}-\mathrm{C}(\mathrm{OH})-\mathrm{CH}_{3}\right), 2.30-2.50$ (Ar$\left.\mathrm{CO}-\mathrm{CH}_{3}\right), 2.90-3.79\left(\mathrm{Ar}-\mathrm{O}-\mathrm{CH}_{3}\right), 3.79-4.20\left(\mathrm{Ar}-\mathrm{CH}_{2}-\mathrm{Ar}\right)$, 5.28-5.43 $\left(\mathrm{Ar}_{2}-\mathrm{C}(\mathrm{OH})-\mathrm{CH}_{3}\right), 5.97-6.40$ (aromatic $\left.H\right)$, 7.298.00 (naphthyl $H$ ); FT-IR $\left(\mathrm{KBr}, \mathrm{cm}^{-1}\right)$ : $3450(-\mathrm{OH}), 2938$, $2832\left(-\mathrm{CH}_{3}\right), 1701(\mathrm{C}=\mathrm{O}), 1598$ (aromatic $\left.\mathrm{C}=\mathrm{C}\right), 1107(\mathrm{Ar}-$ $\left.\mathrm{O}-\mathrm{CH}_{3}\right)$.

6c: Yield: $25 \%$ (light yellow powder); ${ }^{1} \mathrm{H} \mathrm{NMR}\left(\mathrm{CDCl}_{3}, 400\right.$ $\mathrm{MHz}, \delta, \mathrm{ppm}): 1.84-2.04\left(\mathrm{Ar}_{2}-\mathrm{C}(\mathrm{OH})-\mathrm{CH}_{3}\right), 2.33-2.50(\mathrm{Ar}-$ $\left.\mathrm{CO}-\mathrm{CH}_{3}\right), 2.90-3.72\left(\mathrm{Ar}-\mathrm{O}-\mathrm{CH}_{3}\right), 3.72-4.16\left(\mathrm{Ar}-\mathrm{CH}_{2}-\mathrm{Ar}\right)$, 5.20-5.35 $\left(\mathrm{Ar}_{2}-\mathrm{C}(\mathrm{OH})-\mathrm{CH}_{3}\right), 5.85-6.32$ (aromatic $\left.H\right)$, 7.337.63 (biphenyl $H$ ).; FT-IR $\left(\mathrm{KBr}, \mathrm{cm}^{-1}\right)$ : 3504 (-OH), 2938, 
<smiles>COc1cc(OC)c(C(C)=O)c(OC)c1</smiles>

Scheme 1. Addition-condensation of 1 with formaldehyde.

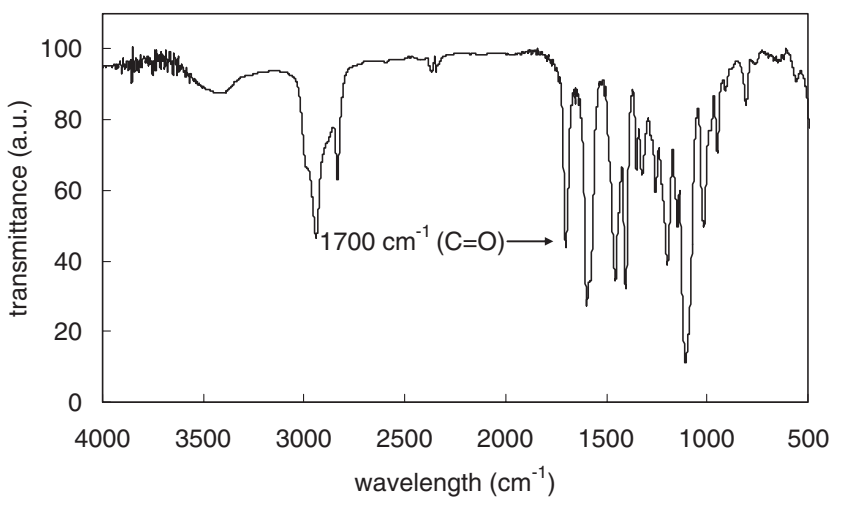

Figure 1. FT-IR spectrum of 3.

$2832\left(-\mathrm{CH}_{3}\right), 1701(\mathrm{C}=\mathrm{O}), 1598$ (aromatic $\left.\mathrm{C}=\mathrm{C}\right), 1106(\mathrm{Ar}-$ $\left.\mathrm{O}-\mathrm{CH}_{3}\right)$.

6d: Yield: $8 \%$ (light orange powder); ${ }^{1} \mathrm{H} \mathrm{NMR}\left(\mathrm{CDCl}_{3}, 400\right.$ $\mathrm{MHz}, \delta, \mathrm{ppm})$ : $1.68-1.90\left(\mathrm{Ar}_{2}-\mathrm{C}(\mathrm{OH})-\mathrm{CH}_{3}\right), 2.30-2.55(\mathrm{Ar}-$ $\left.\mathrm{CO}-\mathrm{CH}_{3}\right), 3.00-3.67\left(\mathrm{Ar}-\mathrm{O}-\mathrm{CH}_{3}\right), 3.67-4.10\left(\mathrm{Ar}-\mathrm{CH}_{2}-\mathrm{Ar}\right)$, 5.95-6.37 (aromatic $H$ ), 7.80-8.20 (pyrenyl $H$ ).; FT-IR (KBr, $\left.\mathrm{cm}^{-1}\right): 3465(-\mathrm{OH}), 2938,2832\left(-\mathrm{CH}_{3}\right), 1700(\mathrm{C}=\mathrm{O}), 1598$ (aromatic $\mathrm{C}=\mathrm{C}), 1107\left(\mathrm{Ar}-\mathrm{O}-\mathrm{CH}_{3}\right)$.

\section{RESULTS AND DISCUSSION}

\section{2,4,6-Trimethoxyacetophenone Novolac (3)}

The 2,4,6-trimethoxyacetophenone novolac (3) was synthesized according to the procedure described in the experimental section (Scheme 1). The obtained polymer, 3, was well soluble in acetone, tetrahydrofuran (THF), and chloroform, but it was insoluble in methanol and water. The number-average molecular weight $\left(M_{\mathrm{n}}\right)$ and the polydispersity index $\left(M_{\mathrm{w}} / M_{\mathrm{n}}\right)$ of $\mathbf{3}$ were found to be 4800 and 1.3 , respectively.

By analyzing the FT-IR (Figure 1), ${ }^{1} \mathrm{H}$ NMR (Figure 2) and ${ }^{13} \mathrm{C}$ NMR spectra (Figure 3 ) of $\mathbf{3}$, it was confirmed that $\mathbf{3}$ is an acetyl group-containing novolac. During polymerization, there is a possibility of side reactions occurring at the acetyl moiety. The prime possibility is the occurrence of the additioncondensation reaction between an acetyl group and an unreacted carbon of the substrate. If this reaction did occur during polymerization, a peak indicating the presence of a ternary (around $54.0 \mathrm{ppm}$ ) or quaternary (around $13.0 \mathrm{ppm}$ ) carbon atom from a carbonyl group should have been observed in the ${ }^{13} \mathrm{C} \mathrm{NMR}$ spectrum of $\mathbf{3}$; however, no such peak appeared in the spectrum. The second possibility is the occurrence of acid-catalyzed aldol condensation between two

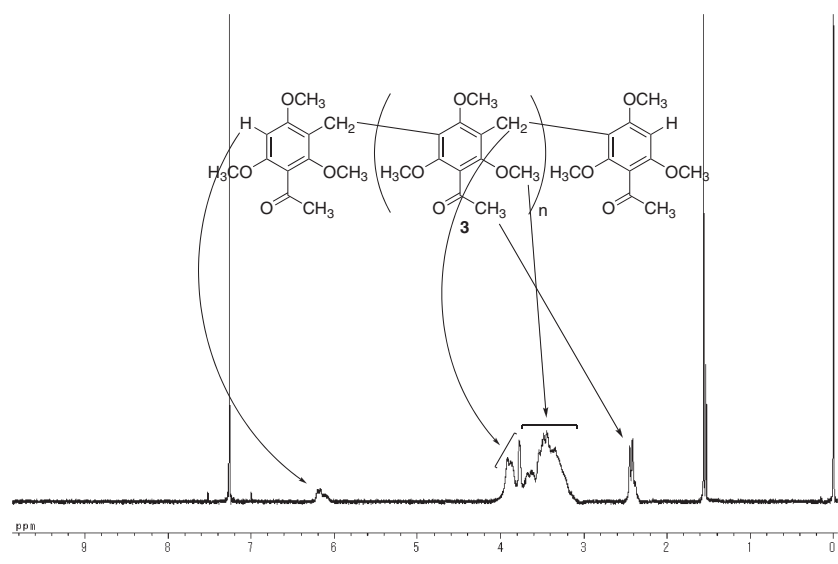

Figure 2. ${ }^{1} \mathrm{H}$ NMR spectrum of 3 in $\mathrm{CDCl}_{3}$.

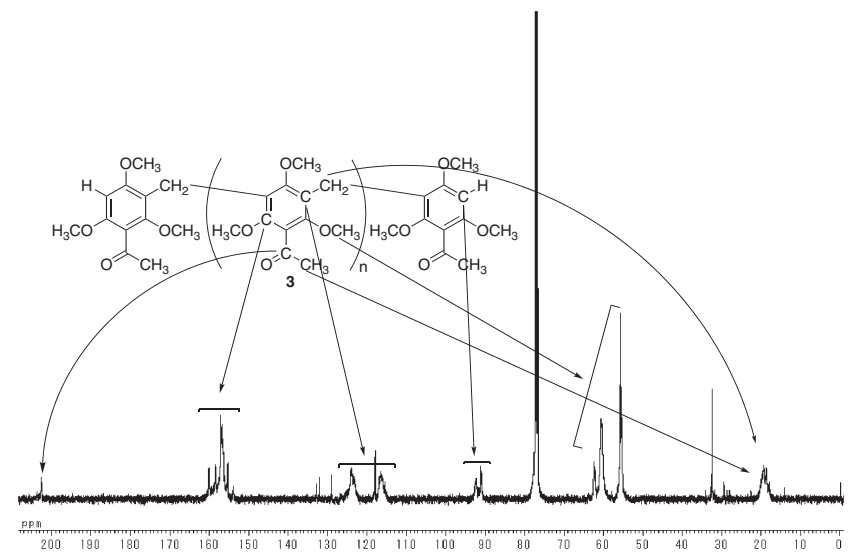

Figure 3. ${ }^{13} \mathrm{C}$ NMR spectrum of 3 in $\mathrm{CDCl}_{3}$.

acetyl groups of $\mathbf{1}$ or that between an acetyl group of $\mathbf{1}$ and formaldehyde. However, no peak corresponding to an $\alpha, \beta$ unsaturated ketone moiety that resulting from the above mentioned aldol condensation was detected in the FT-IR spectrum of $\mathbf{3}$; in addition, the ${ }^{13} \mathrm{C}$ NMR spectrum of $\mathbf{3}$ did not show peaks corresponding to carbonyl carbon (approximately $190.0 \mathrm{ppm}$ ) and vinyl carbon (overlapping with peaks corresponding to other moieties) of $\alpha, \beta$-unsaturated ketone. These results confirm that no side reactions occur at the site of the acetyl group during the addition-condensation of $\mathbf{1}$ with formaldehyde.

The yield of $\mathbf{3}$ was $32 \%$, which is considerably lower than the yield of the polymer $(60 \%)$ synthesized by the additioncondensation of 1,3,5-trimethoxybenzene (2) with formaldehyde at room temperature for $2 \mathrm{~h}$. Furthermore, during the addition-condensation of $\mathbf{1}$ with formaldehyde at room temperature for $2 \mathrm{~h}$, no polymer was obtained when the reaction mixture was poured into methanol. This is because the reactivity of the benzene ring in $\mathbf{1}$ is lower than that of the benzene ring in $\mathbf{2}$ due to the presence of the electronwithdrawing acetyl group in $\mathbf{1}$; consequently, the yield of $\mathbf{3}$ decreased. 


\section{2,4,6-Trimethoxyacetophenone-1,3,5-Trimethoxybenzene} Novolac (4)

The investigation of the characterization results of $\mathbf{3}$, which was obtained by the addition-condensation of $\mathbf{1}$ with formaldehyde, revealed that $\mathbf{3}$ can be used as a reactive polymer. However, in order to use this polymer as a reactive novolac, it should be possible to control the reactivity of the obtained reactive novolac by varying the abundance ratio of the acetyl group in the polymer. The polymerization of $\mathbf{1}, \mathbf{2}$ and formaldehyde with a feed ratio of 1:1:2 was carried out, and the desired polymer, $\mathbf{4}$, was obtained in $22 \%$ yield. The ${ }^{1} \mathrm{H}$ NMR and FT-IR spectra of $\mathbf{4}$ suggested the presence of a phenylene-methylene group, a methoxy group, and an acetyl group (Figures 4 and 5). Addition-condensation with different feed ratios of $\mathbf{1}$ and $\mathbf{2}$ was carried out in order to investigate the difference in reactivities between $\mathbf{1}$ and $\mathbf{2}$. The results of the

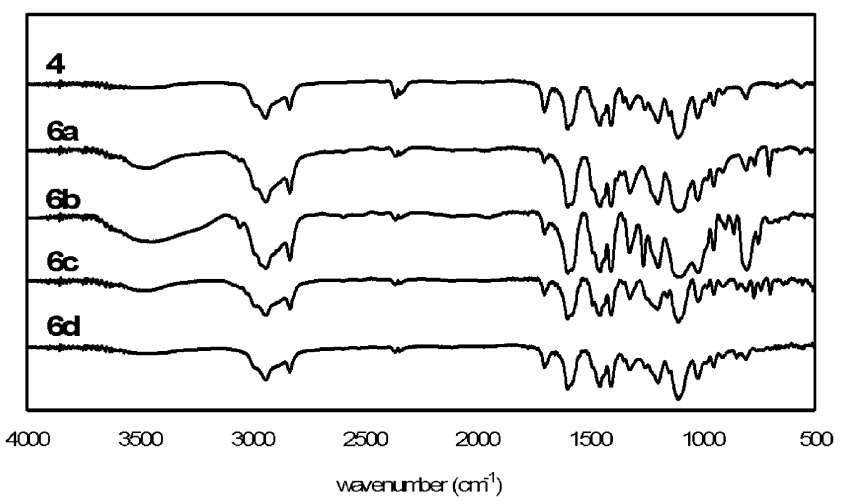

Figure 4. FT-IR spectra of 4 and $6 a-6 d$.

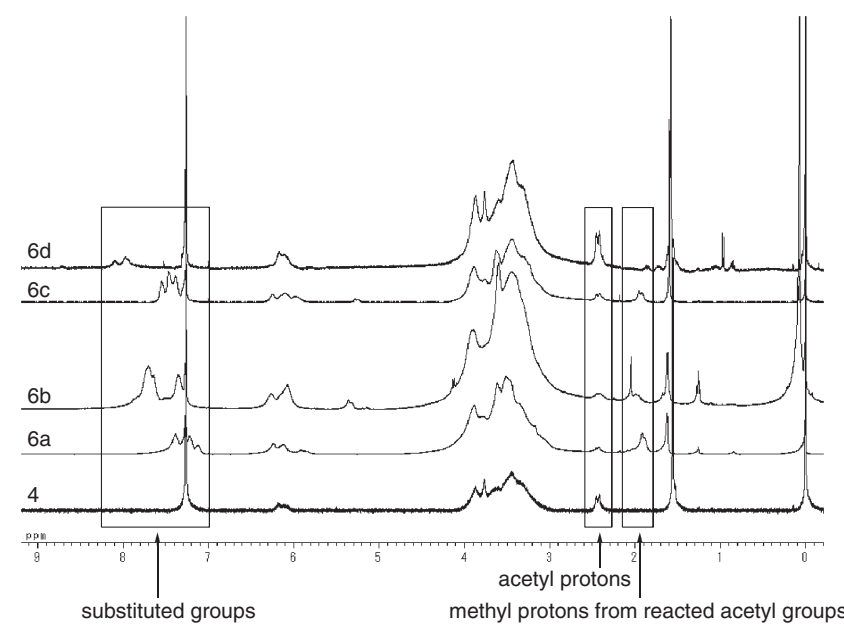

Figure 5. ${ }^{1} \mathrm{H}$ NMR spectra of 4 and $\mathbf{6 a}-\mathbf{6 d}$ in $\mathrm{CDCl}_{3}$.
Table I. Addition-condensation of 1 and 2 with formaldehyde

\begin{tabular}{ccccccc}
\hline run & $\begin{array}{c}\text { feed ratio } \\
(\mathbf{1 : 2})\end{array}$ & $\begin{array}{c}\text { time } \\
(\mathrm{h})\end{array}$ & $\begin{array}{c}\text { yield } \\
(\%)\end{array}$ & $M_{\mathrm{n}}$ & $M_{\mathrm{w}} / M_{\mathrm{n}}$ & $\begin{array}{c}\text { acetophenone content } \\
(\%)\end{array}$ \\
\hline 1 & $10: 0$ & 15 & $32^{* 1}$ & 4800 & 1.3 & 100 \\
2 & $5: 5$ & 6 & $22^{* 2}$ & 5100 & 1.3 & 25 \\
3 & $4: 6$ & 12 & 17 & 4200 & 1.2 & 20 \\
4 & $3: 7$ & 12.5 & 25 & 3900 & 1.8 & 18 \\
5 & $2: 8$ & 13.5 & 34 & 4300 & 1.9 & 15 \\
6 & $1: 9$ & 8 & 52 & 8800 & 4.1 & 5 \\
7 & $0: 10$ & 8 & $61^{* 3}$ & 7500 & 4.8 & - \\
\hline
\end{tabular}

${ }^{* 1}$ : polymer $3 .{ }^{* 2}$ : polymer $4 .{ }^{* 3}$ : polymer 7 .

various polymerizations are summarized in Table I, and the acetophenone unit content was estimated from the ${ }^{1} \mathrm{H}$ NMR spectra. During the polymerization of $\mathbf{1}, \mathbf{2}$ and formaldehyde (Table I, run 2), the backbone of the polymer may undergo branching at the location of the 1,3,5-trimethoxybenzene moiety. The occurrence of this branching reaction can be confirmed by evaluating the integral ratio of the acetyl, methylene or methoxy, and aromatic protons from the ${ }^{1} \mathrm{H}$ NMR spectrum of 4 (Figure 5). The abundance ratio of each moiety (m:n:1, Scheme 2) was found to be 1.0:1.5:2.1. This result indicated that 2 , which could be polymerized with formaldehyde even under mild reaction conditions as mentioned above, reacted easily with carbocations or methylol carbons at three reactive points, resulting in the production of a large number of branched moieties. When the polymerization was carried out with a low feed ratio of 2 (Table I, runs 2-5), branching of the polymers did not significantly affect the $M_{\mathrm{w}} / M_{\mathrm{n}}$ values of the polymers; however, on carrying out polymerization with relatively high feed ratios of 2 (runs 6 and 7), the $M_{\mathrm{w}} / M_{\mathrm{n}}$ values of the products were observed to increase significantly with the degree of branching $\left(M_{\mathrm{w}} / M_{\mathrm{n}}\right.$ in run 6: $4.1 ; M_{\mathrm{w}} / M_{\mathrm{n}}$ in run $\left.7: 4.8\right)$. Furthermore, it was observed that the content of acetophenone units in the polymer backbones decreased with the drop in the feed ratio of $\mathbf{1}$; however, the ratio of the acetophenone moieties in the polymer backbone did not coincide with the feed ratio of $\mathbf{1}$, but was found to be lower than the feed ratio. Also, the yield of the polymeric product increased as the feed ratio of $\mathbf{1}$ decreased. These results indicated that the reactivity of $\mathbf{1}$ was lower than that of $\mathbf{2}$.

\section{Grignard Reaction}

In organic chemistry, Grignard reactions are commonly carried out for the substitution of ketones with hydroxyl groups; these reactions have a high conversion rate. In general, the reactivity of a polymer is lower than that of its monomer; however, Grignard reactions can proceed via the interaction of<smiles>COc1cc(OC)cc(OC)c1</smiles><smiles></smiles>

Scheme 2. Addition-condensation of $\mathbf{1}$ and 2 with formaldehyde. 


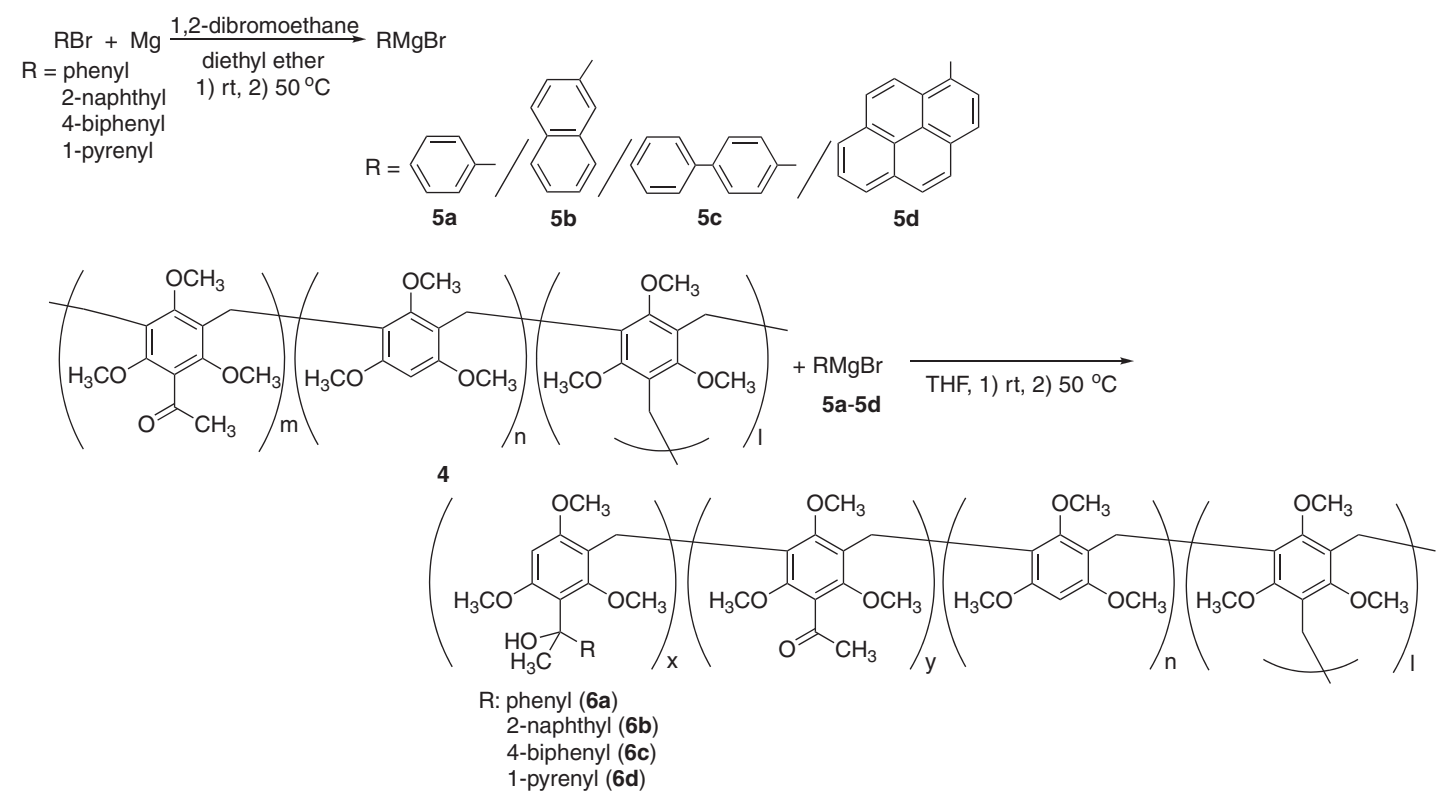

Scheme 3. Grignard reaction of 4 with various organomagnesium compounds $(\mathbf{5 a}-\mathbf{5 d})$.

Table II. Results of Grignard reactions of 4

\begin{tabular}{cccccc}
\hline polymer & $\mathrm{RMgBr}$ & yield (\%) & $M_{\mathrm{n}}$ & $M_{\mathrm{w}} / M_{\mathrm{n}}$ & $\begin{array}{c}\text { conversion of the } \\
\text { obtained polymer }\end{array}$ \\
\hline $\mathbf{4}$ & - & - & 5100 & 1.3 & - \\
$\mathbf{6 a}$ & $\mathrm{R}=$ phenyl & 40 & 6100 & 1.1 & $70 \%$ \\
$\mathbf{6 b}$ & $\mathrm{R}=$ naphthyl & 37 & 6000 & 1.3 & $50 \%$ \\
$\mathbf{6 c}$ & $\mathrm{R}=$ biphenyl & 25 & 6200 & 1.2 & $50 \%$ \\
6d & $\mathrm{R}=$ pyrenyl & 8 & 6000 & 1.3 & $15 \%$ \\
\hline
\end{tabular}

the Grignard reagent with the backbone or side chains of polymers. Considering the above possibility, Grignard reactions of $\mathbf{4}$ were carried out with bulky Grignard reagents $(\mathbf{5 a}-$ 5d) in order to investigate the reactivity of the acetyl groups; furthermore, $\mathbf{4}$ (prepared by the addition-condensation of $\mathbf{1}$ and $\mathbf{2}$ in a feed ratio of 1:1 with formaldehyde) was selected over $\mathbf{3}$, because 4 is expected to show lower steric hindrance at the acetophenone moieties than 3. Various Grignard reagents (5a-5d) were prepared from aryl bromides according to the procedure mentioned in the experimental section (Scheme 3). Then, Grignard reactions of $\mathbf{4}$ were carried out with nontitrated these reagents in order to functionalize $\mathbf{4}$, which would in turn afford the desired products (6a-6d) (Table II). The FTIR spectra of $\mathbf{6 a - 6 d}$ clearly showed a peak corresponding to the hydroxyl group at around $3500 \mathrm{~cm}^{-1}$ (Figure 4). The ${ }^{1} \mathrm{H}$ NMR spectra of each polymer (6a-6d) (Figure 5) showed peaks at 1.68-2.13 ppm, 2.30-2.51 ppm, 5.85-6.40 ppm, and 7.06$8.20 \mathrm{ppm}$, respectively. These peaks respectively correspond to the methyl protons arising from the reactions at acetyl groups, methyl protons of the acetyl groups, the aromatic protons of starting material $\mathbf{4}$, and the aromatic protons introduced via the Grignard reaction. These results suggested that the Grignard reactions of $\mathbf{4}$ with $\mathbf{5 a}-\mathbf{5 d}$ were successfully carried out. Furthermore, the conversion rate of the acetyl
Table III. Solution properties of $\mathbf{4}$ and $\mathbf{6 a - 6 d}$ in a dilute THF solution

\begin{tabular}{cccc}
\hline polymer & aryl group & $a^{* 1}$ & $\log K^{* 1}$ \\
\hline $\mathbf{4}$ & - & 0.37 & -2.89 \\
$\mathbf{6 a}$ & phenyl & 0.33 & -2.65 \\
$\mathbf{6 b}$ & naphthyl & 0.56 & -3.47 \\
$\mathbf{6 c}$ & biphenyl & 0.28 & -2.36 \\
$\mathbf{6 d}$ & pyrenyl & 0.28 & -2.36 \\
\hline
\end{tabular}

${ }^{* 1}$ : Mark-Houwink-Sakurada equation $\left([\eta]=K \mathrm{M}^{a}\right)$

groups to hydroxymethines was confirmed by investigating the ${ }^{1} \mathrm{H}$ NMR spectra (Table II) of the products. The conversion rate of the obtained polymers decreased with an increase in the size of the aryl group in the Grignard reagent. This decrease was due to the increase in the steric hindrance between $\mathbf{4}$ and the Grignard reagents. Furthermore, all the obtained polymers $(\mathbf{3}, \mathbf{4}, \mathbf{6 a}-\mathbf{6 c})$ exhibited film-forming properties; therefore, these polymers can be expected to possess good processability and good adhesive properties.

\section{Solution Properties}

The solution properties of $\mathbf{6 a - 6} \mathbf{d}$ in dilute THF solutions were estimated by using a SEC-VISC-RALLS system (Viscotek) (Table III). ${ }^{5(\mathrm{~b}, \mathrm{f}), 8}$ In the cases of $\mathbf{6 a}, \mathbf{6 c}$ and $\mathbf{6 d}$, the values of the parameter $a$ in the Mark-Houwink-Sakurada equation $\left([\eta]=K \mathrm{M}^{a}\right)$ were found to be $0.33,0.28$ and 0.28 , respectively. These results indicate that in dilute THF solutions, $\mathbf{6 a}, \mathbf{6 c}$ and $\mathbf{6 d}$ have compactly folded spherical structures, as in the case of conventional novolacs. ${ }^{9}$ In contrast, the value of $a$ for $\mathbf{6 b}$ was found to be 0.56 . Since this value is slightly lower than that observed in the case of linear polymers (approximately 0.6-0.8), we speculate that in dilute THF solution, $\mathbf{6 b}$ has a random coil structure, which is close to a spherical structure. The higher value of $a$ in the case of $\mathbf{6 b}$ as 
opposed to that in the case of $\mathbf{6 c}$, whose conversion rate was the same as that of $\mathbf{6 b}$, was attributed to the difference between the mobilities of the naphthyl group and the biphenyl group. In general, organosoluble phenolic resins essentially form spherical structures in dilute solutions. To accommodate a naphthyl group into the side chains of resins, the main chain relaxes to form a random coil due to the steric hindrance from the naphthyl group. However, in the case of $\mathbf{6 c}$, each phenyl moiety in the biphenyl group is capable of rotating the $\mathrm{C}-\mathrm{C}$ bond and thus this group does not inhibit the folding of the polymer main chain. Therefore, the value of $a$ in the case of $\mathbf{6 c}$ is lower than that in the case of $\mathbf{6} \mathbf{b}$ because of this folded spherical structure. The value of parameter $a$ of $\mathbf{6 a}$ was lower than that of $\mathbf{6 b}$, irrespective of higher conversion. This result is probably attributed to the size of a phenyl group, which is smaller than those of other groups. That is, it is difficult for phenylmagnesium bromide to change the conformation of the 4 significantly, even with high conversion. On the other hand, the value of the parameter $a$ of $\mathbf{6 d}$ was lower than that of $\mathbf{6 b}$, irrespective of the large size of a pyrenyl group. This result is probably attributed to the lower conversion (15\%) of the polymer.

\section{Thermal Properties}

The thermal properties of the obtained polymers $(3, \mathbf{4}, \mathbf{6 a}-$ 6c) were examined by thermogravimetric analyses (TGA) under a nitrogen atmosphere. The results of the TGA are shown in Figure 6. The $T_{\mathrm{d} 5}$ (temperature at $5 \%$ loss in weight) values of 3, 4, and 1,3,5-trimethoxybenzene novolac (7, Table I, run 7) were found to be 356,361 , and $367^{\circ} \mathrm{C}$, respectively (Table IV). These results suggested that the thermal decompositions of these polymers occurred preferentially at the methoxy and acetyl groups.

TGA of polymers 6a-6c were also carried out (Figure 6). From the $T_{\mathrm{d} 5}$ values of $\mathbf{6 a}-\mathbf{6 c}\left(\mathbf{6 a}: 351^{\circ} \mathrm{C}, \mathbf{6 b}: 354{ }^{\circ} \mathrm{C}, \mathbf{6 c}\right.$ : $360^{\circ} \mathrm{C}$ ) (Table IV), it was apparent that the thermal stability of 4 did not change significantly when these compounds were reacted with Grignard reagents. For example, in the case of $\mathbf{6 b}$, the introduction ratio of a naphthalene moiety was estimated to be $13 \%$ from the ${ }^{1} \mathrm{H}$ NMR spectrum of $\mathbf{6 b}$. Although the conversion rate of the acetyl group was low, the TGA results indicated that the obtained polymers retained the thermal properties even after their reaction with Grignard reagents. In other words, we have demonstrated that by carrying out Grignard reaction, it is possible to introduce additional functional groups into novolacs, without changing their thermal properties. Therefore, Grignard reaction can prove to be an excellent method for modifying the functional characteristics of novolacs.

\section{CONCLUSIONS}

In order to prepare novel functional novolacs, we carried out the addition-condensation of $\mathbf{1}$ with formaldehyde and that of $\mathbf{1}$ and $\mathbf{2}$ with formaldehyde. Both the polymerization reactions proceeded without the occurrence of any side reactions. In the

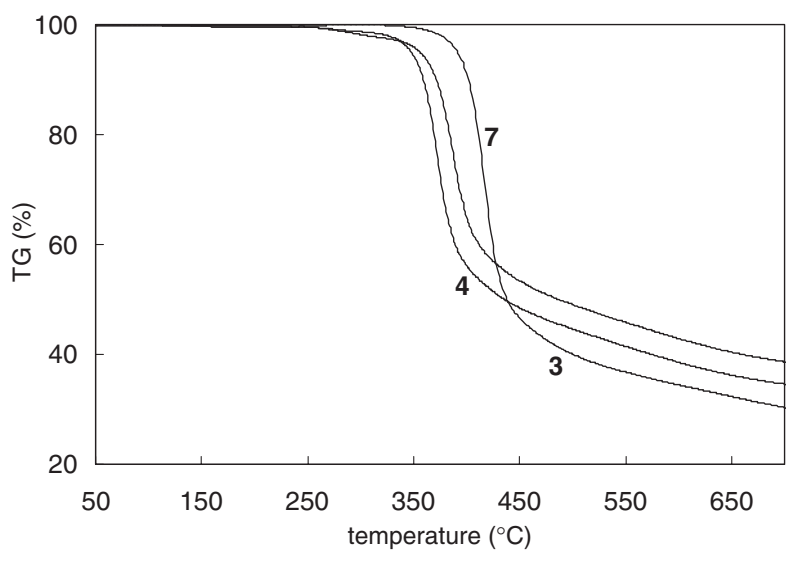

(a)

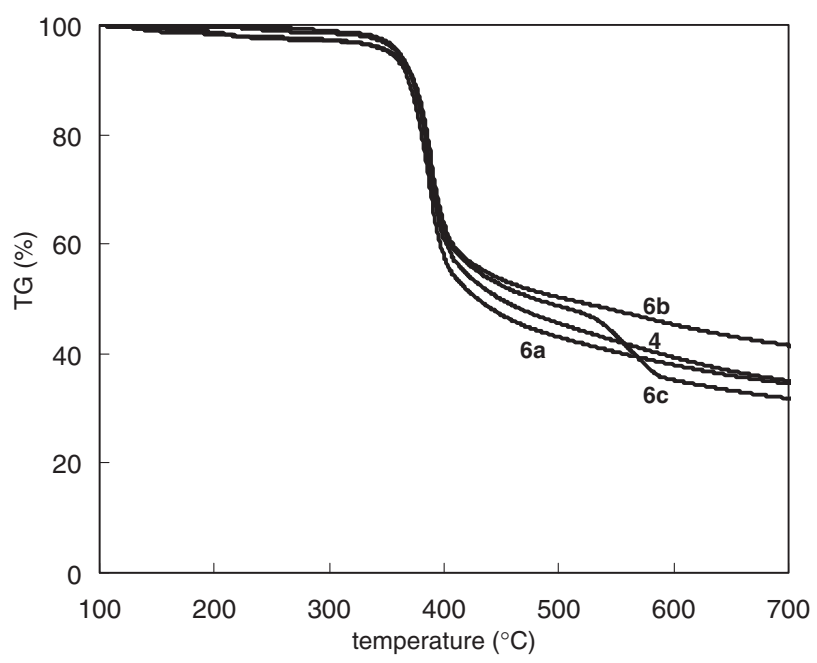

(b)

Figure 6. Thermogravimetric analyses of 3,4 and 7 (a), and 4 and 6a-6c (b).

Table IV. TG analyses of $3,4,6 a-6 c$ and 7

\begin{tabular}{ccccccc}
\hline polymer & $\mathbf{7}$ & $\mathbf{3}$ & $\mathbf{4}$ & $\mathbf{6 a}$ & $\mathbf{6 b}$ & $\mathbf{6 c}$ \\
\hline$T_{\mathrm{d} 5}{ }^{* 1}\left({ }^{\circ} \mathrm{C}\right)$ & 367 & 356 & 361 & 351 & 354 & 360 \\
\hline & $* 1:$ Temperature at $5 \%$ loss in weight.
\end{tabular}

case of polymerization of $\mathbf{1}$ and $\mathbf{2}$ with formaldehyde, the contents of the acetophenone moieties could be controlled by varying the feed ratio. Furthermore, the polymers synthesized by the above polymerization were made to react with Grignard reagents to functionalize the acetophenone moieties of the polymer. The results of the Grignard reactions indicated that phenolic resins substituted with acetyl groups can be used as reactive polymers. The thermal stabilities of the polymers were sustained even after the Grignard reactions. This suggests that functionalized polymers can sustain heat up to approximately $30{ }^{\circ} \mathrm{C}$; thus, acetophenone-containing novolacs can be employed as adhesives without solder, coating materials, etc. By studying the solution properties of the polymers, we observed that in dilute THF solutions, almost all polymers exhibited 
compactly folded spherical structures, similar to conventional phenolic resins; however, only the polymer $\mathbf{6 b}$, in which the side chains consisted of naphthalene moieties, showed the random coil formation. The acetyl group-containing alkoxylated phenolic novolacs synthesized in our study also exhibited a film-forming property; hence, these novolacs can act as highperformance resins with good processability and high resistance to heat.

Acknowledgment. This work was partially supported by SORST program from JST and Industrial Technology Research \& Development Grant (04A23030) from NEDO of JAPAN.

Received: December 16, 2008 Accepted: January 27, 2009 Published: March 11, 2009

\section{REFERENCES}

1. A. Knop and L. A. Pilato, "Phenolic Resins." Springer-verlag, Berlin, 1985.

2. G. Konishi, J. Syn. Org. Chem. Jpn., 66, 705 (2008).

3. a) D. Crespy, M. Bozonnet, and M. Meier, Angew. Chem., Int. Ed., 47, 3322 (2008).

b) T. Takeichi, T. Kawauchi, and T. Agag, Polym. J., 40, 1121 (2008). c) J. Kadota, T. Fukuoka, H. Uyama, K. Hasegawa, and S. Kobayashi, Macromol. Rapid Commun., 25, 441 (2004).

d) T. Nemoto, I. Amir, and G. Konishi, Polym. J., 41, 338 (2009).

e) J. Cui, Y. Yan, J. Liu, and Q. Wu, Polym. J., 40, 1067 (2008).

f) B. S. Kaith and S. Kalia, Polym. J., 39, 1319 (2007).

g) G. Pan, Z. Du, C. Zhang, C. Li, X. Yang, and H. Li, Polym. J., 39,
478 (2007).

h) K. Suzuki, H. Matsumoto, M. Minagawa, M. Kimura, and A. Tanioka, Polym. J., 39, 1128 (2007).

4. D.-M. Shin, N. Ozeki, Y. Nakamoto, and G. Konishi, Macromol. Res., 14, 255 (2006).

5. a) T. Kimura, Y. Nakamoto, and G. Konishi, Polym. J., 38, 606 (2006).

b) T. Nemoto, T. Ueno, M. Nishi, D.-M. Shin, Y. Nakamoto, and G. Konishi, Polym. J., 38, 1278 (2006).

c) J. Jeerupan, G. Konishi, T. Nemoto, D. M. Shin, and Y. Nakamoto, Polym. J., 39, 762 (2007).

d) A. Kobayashi and G. Konishi, Polym. J., 40, 590 (2008).

e) T. Nemoto and G. Konishi, Polym. J., 40, 651 (2008).

f) T. Nemoto, G. Konishi, T. Arai, and T. Takata, Polym. J., 40, 622 (2008).

6. a) S. Sugawara, M. Tomoi, and T. Oyama, Polym. J., 39, 129 (2007). b) K. Tsuchiya, Y. Shibasaki, and M. Ueda, Polym. J., 39, 442 (2007). c) T. Nishikubo, H. Kudo, and H. Nomura, Polym. J., 40, 310 (2008). d) Y. Chujo, I. Tomita, Y. Higashiguchi, and T. Saegusa, Macromolecules, 24, 3010 (1991).

e) H. Ritter and R. Sperber, Macromolecules, 27, 5919 (1994).

f) T. F. Scott, A. D. Schneider, W. D. Cook, and C. N. Bowman, Science, 308, 1615 (2005).

g) N. N. Ghosh, B. Kiskan, and Y. Yagci, Prog. Polym. Sci., 32, 1344 (2007).

h) K. Mizoguchi and M. Ueda, Polym. J., 40, 645 (2008).

i) N. Matsumi and Y. Chujo, Polym. J., 40, 77 (2008).

7. T. Nemoto, I. Amir, and G. Konishi, Polym. J., 41, 389 (2009).

8. T. Fukuoka, H. Uyama, and S. Kobayashi, Macromolecules, 36, 8213 (2003).

9. a) T. Yamagishi, R. Takahashi, D. Nagata, G. Konishi, and Y. Nakamoto, Kobunshi Ronbunshu, 60, 200 (2003).

b) S. Ishida, T. Kitagawa, Y. Nakamoto, and K. Kaneko, Polym. Bull., 10, 533 (1983).

c) K. Kamide and Y. Miyakawa, Makromol. Chem., 179, 359 (1978). 